Water Pollution XV 147

\title{
NINE STRATEGIES TO PROTECT AND ENHANCE WATERWAYS
}

\author{
GLENN BROWNING \\ Healthy Land and Water, Australia
}

\begin{abstract}
In Queensland, the State Government legislation requires all new development to reduce stormwater pollutant loads discharging to the creek (in Brisbane for example, total suspended solids needs to be reduced by $80 \%$, total phosphorus by $60 \%$ and total nitrogen by $45 \%$ ). These simple targets have driven millions of dollars of investment throughout the State. Healthy Land and Water (HLW), a Brisbanebased natural resource management group were given the opportunity to review these stormwater design objectives for the State Government. Whilst it is acknowledged that they are a much-needed step to limiting our ecological impact, our research has raised questions about whether this is the best way of managing our waterway assets. By assessing the stormwater pollution targets using a first principles risk analysis, it was shown that there are fundamental inefficiencies with this approach. The current approach places no incentive on hazard minimisation or avoidance, it makes no distinction as to the downstream waterway value and it provides no opportunity to invest in value restoration, reconnection or conservation efforts. To address these issues HLW have created Strategic Waterways, a tool for categorising and prioritising waterway investments. The tool uses a risk/benefit model to assess, diagnose and then plan the treatment of various waterway ailments. Most importantly it allows for nine unique strategies to managing waterway value where previously there was only one or two. Strategies include: (1) value conservation, (2) value protection, (3) hazard minimisation, (4) risk mitigation, (5) value reconnection, (6) value creation, (7) gamechangers, (8) strategic offsets, and (9) minimum requirements. This paper explains the practical differences in these approaches and empowers waterway managers to build a balanced portfolio of waterway investments to create the biggest possible ecological return on investment.
\end{abstract}

Keywords: stormwater, waterways, management, strategy, pollution, risk, values, prioritisation.

\section{INTRODUCTION}

Currently the development industry in Queensland, Australia has one typical strategy for managing stormwater pollution; stormwater runoff from new housing estates is filtered via bioretention basins (vegetated sand filter beds) before it discharges to the drainage system and receiving waterways. Although this provision reduces potential environmental harm it does not consider the health condition of the local waterway [1] nor the extensive legacy issues across our urban waterways [2]. It also does not allow for hazard minimisation nor waterway improvement or value creation strategies [3], [4]. Monitoring of the waterways [5] suggests there is much work to do to ease current waterway pressures and we are further adding to their pressures through urban densification and climate change. Essentially, as an industry we are failing to achieve the objectives of the legislation under the Environmental Protection (Water) Policy [6] to "protect and enhance water values", After reviewing the science and the practice, HLW have found more can be achieved by taking a strategic approach to waterway management. This involves directing proportionate and appropriate effort and investment to locations where it can create the biggest impact. In circumstances where there is limited environmental funding, this approach to maximise ecological and social return on investment (ROI) is imperative. 


\subsection{Methodology for understanding the problem}

HLW have previously assessed and documented the state of waterway management in Queensland in 2014 and again in 2017 [7]. More recently, HLW and Alluvium undertook an extensive review of scientific literature [1] throughout Queensland and internationally focusing particularly on the hydrologic and water quality impacts of urban development on waterways. Informed by this research, the team also held eight half-day workshops with industry leaders and key councils across the state [2] to gather valuable insight and a further appreciation into the current science and stormwater management practices across the State.

\subsection{Proposed solution}

To diversify the portfolio of activities funded and improve our ecological return on investment, HLW has created a new decision support tool to improve waterway condition called Strategic Waterways that has a 5-step process:

1. Condition assessment: What is the current health status of the waterway?

2. Diagnosis: What is causing poor waterway health?

3. Treatment strategy: What treatment options should be used?

4. Triage: Which sections of the waterway has the highest priority?

5. Monitoring: How effective is our strategy?

This paper expands on and develops the theory behind each of the nine treatment strategies (i.e. Step 3) and how each strategy can be used most efficiently and effectively.

\subsection{Target audience}

This highly adaptable tool can potentially be used to assess many other types of engineering risks, such as safety, bushfire and heat risk, natural areas management, and flood management. HLW's Strategic Waterways tool will be useful for a variety of decision makers in local governments including:

- Waterway and catchment managers and planners;

- Stormwater drainage engineers;

- Asset managers, budgeting and finance.

1.4 How does the strategic waterways tool work?

Strategic Waterways provides users with a questionnaire about hazards "R", values " $G$ " and needs "B". It then classifies a given waterway with a "RGB" colour code. A score of 0 indicates a low score and 250 indicates a high score. Since "RGB" colour coding can visually represent a diverse range of colours the system is quite versatile. Details of the colour coding system are outlined below:

- "Red" indicates how hazardous the catchment is;

- Where a hazard overlaps with a value it forms a risk ("Yellow");

- "Green" indicates how valued the catchment/waterway is;

- Where a value overlaps with a need it forms an opportunity ("Cyan");

- "Blue" indicates where there is the opportunity to recover or enhance value;

- Where a hazard can fulfil a need it forms a gamechanger ("Magenta"). 
The unique colour coding system means it is easy to visualise the combination of waterway hazards, values and needs. Once an "RGB" colour code is determined this helps diagnose what the waterway actually needs, and a corresponding treatment strategy can be assigned (Fig. 1). The scoring can also be used to triage and prioritise as well as keep track of improvement strategies. The Strategic Waterways [8] questionnaire and user guide can be downloaded for free from: www.waterbydesign.com.au/resources.

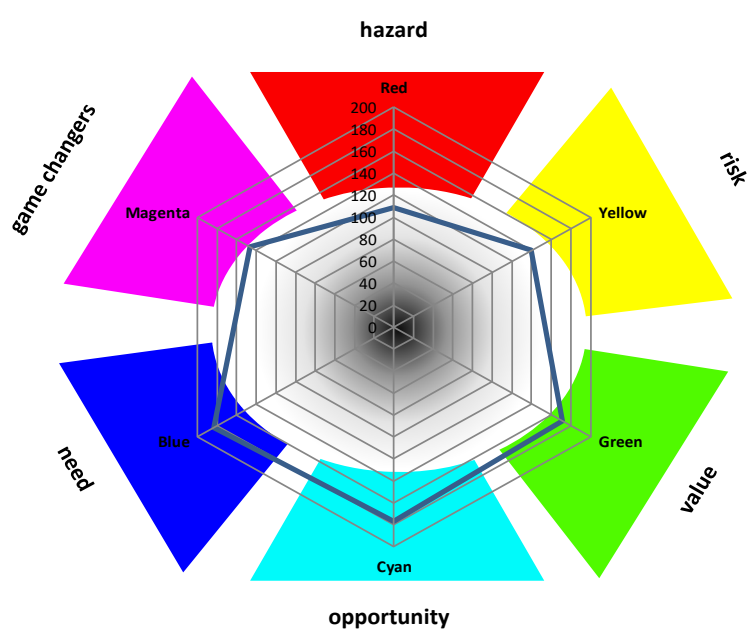

Figure 1: Hazard/value/need plot.

\subsection{Treatment strategies}

Once a waterway diagnosis has been undertaken, a waterway manager can start to assign an appropriate treatment strategy for each section of the waterway. For some pristine waterways, this strategy will focus on conservation, whereas for others the focus may be on hazard reduction. This remainder of this paper concentrates on the nine treatment strategies to improve waterway management including:

- Strategy 1: Value conservation;

- Strategy 2: Value protection;

- Strategy 3: Hazard minimisation;

- Strategy 4: Risk mitigation;

- Strategy 5: Value reconnection;

- Strategy 6: Value creation;

- Strategy 7: Gamechangers;

- Strategy 8: Strategic offsets;

- Strategy 9: Minimum requirements.

The nine strategies detailed above represent a marked improvement in the number of options available to stormwater managers under current Queensland stormwater quality regulations. Taking this nuanced management approach will account for the unique condition, pressures and prospects of each waterway and allow for better investment than standard approaches [8]. 
Strategy aims:

\section{STRATEGY 1: VALUE CONSERVATION}

To maintain existing values;

To manage potential threats;

To inspire further conservation action.

Qualifying criteria:

Waterways and catchments are in pristine condition.

Site profile:

"Eden" (Fig. 2).

Examples:

Daintree Rainforest, Noosa River.

"Green"

RGB Code: $\mathrm{R}=0, \mathrm{G}=250, \mathrm{~B}=0$.

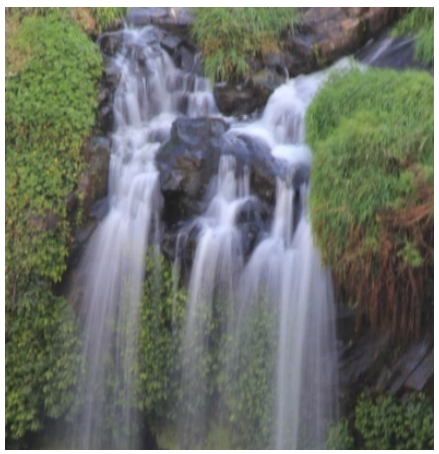

Figure 2: "Eden".

\subsection{Strategy 1a: Manage generic threats}

There is a need to underpin resilience of very high value waterways, that is we need to improve the ability to adapt or bounce back from shocks including:

- Climate impacts (e.g. temperature, flood, drought, bushfire);

- Invasive species (e.g. weeds and exotic fish).

\subsection{Strategy 1b: Protect from future development}

These waterway sites are to be mapped as protected areas under local government planning schemes and its catchments should not be cleared or developed.

\subsection{Strategy 1c: Safeguard perceived value and justify protections}

There is a risk that if these sites are locked up and hidden from view then they will be forgotten about and neglected. So, there is a need to continually demonstrate the value of pristine waterways to society and governments so that they continue to enact policies to keep them in their wild state. This can be achieved through scientific research, education and media. This will help safeguard against government policy changes and future catchment development.

\subsection{Strategy 1d: Celebrate intrinsic value}

By permitting opportunities for society to access and enjoy pristine waterway sites we can improve our understanding of the natural environment and our nature connectedness and this 
may inspire patrons to undertake conservation action. Collecting visitor numbers and visitor feedback will also help to justify continual investment in these wild areas.

Strategy aims:

Qualifying criteria:

Site profile:

Examples: "Green"

\section{STRATEGY 2: VALUE PROTECTION}

To maintain existing waterway values;

To manage potential threats;

To permit a low-impact form of development.

Waterways have high value scores,

Small portions of the catchment may already be cleared of vegetation and have development potential.

"The Shire" (Fig. 3).

Gold Coast Hinterland (e.g. Currumbin Ecovillage).

RGB Code: $\mathrm{R}=0, \mathrm{G}=200, \mathrm{~B}=0$.

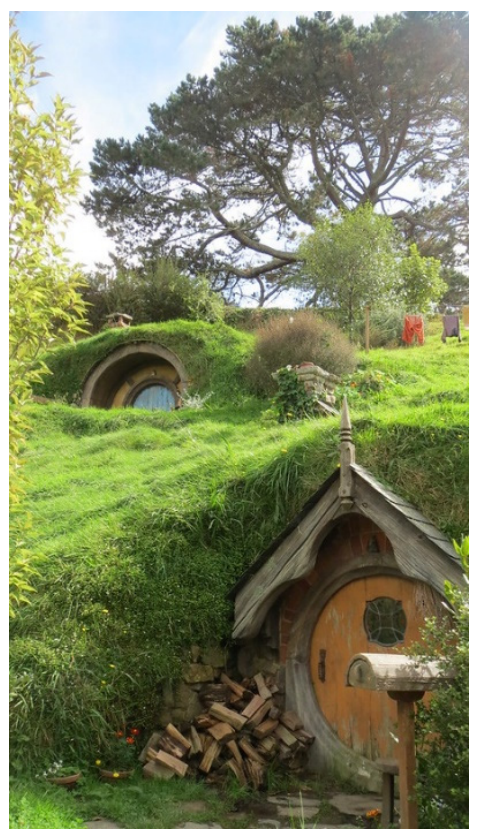

Figure 3: Green roofs as represented in the Hobbit "Shire". (Photo: Sheila Thomson.)

\subsection{Strategy 2a: Manage generic threats}

There is a need to underpin resilience of very high value waterways, that is we need to improve the ability to adapt or bounce back from shocks including:

- Climate impacts (e.g. temperature, flood, drought, bushfire);

- Invasive species (e.g. weeds and exotic fish).

3.2 Strategy $2 \mathrm{~b}$ : Insulate waterways from development threats

Where waterways have high value, but their catchments can still be developed, waterways should be protected at the planning stage with very strict controls on any development. 
Development within these catchments should have a "neutral or beneficial impact" on the local waterway and should employ low-impact design. The ideal development would be almost completely vegetated and would represent best practice in stormwater management with features such as rainwater tanks, permeable driveways and roads and green roofs.

Strategy aims:

\section{STRATEGY 3: HAZARD MINIMISATION}

Qualifying criteria:

Site profile:

Examples:

To control hazards at their source.

Catchments with high pollutant loads.

"A catchment detox".

Industrial areas such as Pinkenba, Port of Brisbane, Rocklea, Wacol, Archerfield, Slacks Creek and Underwood.

"Red" RGB Code: $\mathrm{R}=250, \mathrm{G}=0, \mathrm{~B}=0$.

To devise an adequate pollution abatement program, we need to understand each of the relevant pollutants as described below.

Table 1: Understanding waterway hazards.

\begin{tabular}{|l|l|}
\hline Take an inventory of hazards & $\begin{array}{l}\text { Origins: industrial, commercial, residential or } \\
\text { agricultural } \\
\text { Distribution/prevalence: via GIS Mapping }\end{array}$ \\
\hline Understanding the hazard & $\begin{array}{l}\text { Toxicity/harm } \\
\text { Magnitude and recurrence of pollution events: acute/ } \\
\text { chronic }\end{array}$ \\
\hline Assessment of threat level & $\begin{array}{l}\text { Priority should be given to the highest combined toxicity } \\
\text { and prevalence }\end{array}$ \\
\hline Management of threat & $\begin{array}{l}\text { Can the hazard be practically eliminated or is } \\
\text { containment the best that can hoped for? }\end{array}$ \\
\hline
\end{tabular}

\subsection{Strategy 3a: Reduce pollutant toxicity}

The toxicity of pollutants can be reduced via pollutant avoidance, substitution or control.

Legal controls are quite effective for industrial discharge and commercial products. Acute hazards such as DDT may need a direct ban. These harmful products can often be substituted with less harmful chemicals such as waterway friendly herbicides and pesticides.

Planning controls are quite effective at reducing the toxicity of stormwater discharge for residential areas. Setting water quality targets ensures stormwater is filtered prior to discharge to the creek which reduces contaminant concentrations and toxicity.

\subsection{Strategy 3b: Reduce pollutant prevalence}

The prevalence of waterway hazards and pollutants can be reduced via behaviour change programs and design controls.

Where the hazard is widespread there will be a need to invest in behaviour change programs, e.g. reduction of single-use plastic drink bottles, bags and straws.

Proactive environmental design in residential areas can help to avoid the creation and prevalence of stormwater pollution. Options include passive irrigation, bioretention, rainwater tanks, infiltration systems, permeable driveways and green roofs. 
Strategy aims:

Qualifying criteria:

Site profile:

Examples:

"Yellow"

\section{STRATEGY 4: RISK MITIGATION}

To reduce harm to waterways through hazard mitigation.

Sites where a hazard flows to an area of high value forming a critical vulnerability.

"The Flash Point" (Fig. 4).

Bells Creek, Mango Hill.

RGB Code: $\mathrm{R}=250, \mathrm{G}=250, \mathrm{~B}=0$.

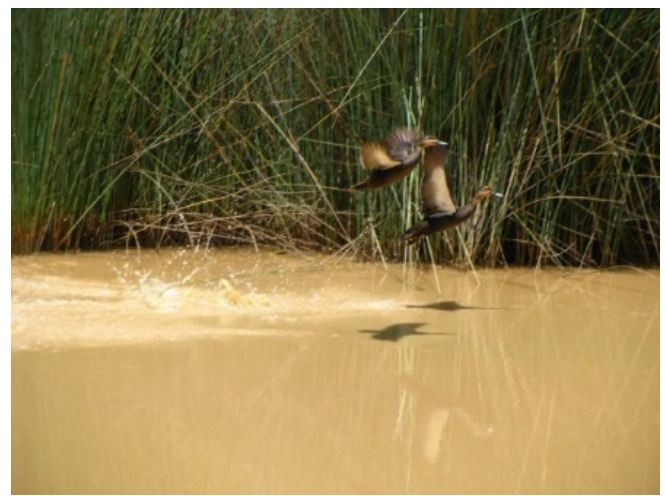

Figure 4: Pristine waterways become polluted with construction sediment.

GIS mapping can highlight key locations where there is an intersection of values and hazards i.e. hotspots. By understanding the risk pathway [9], we then can identify the best strategies and management actions to break the risk path and protect our waterway values (Fig. 5).

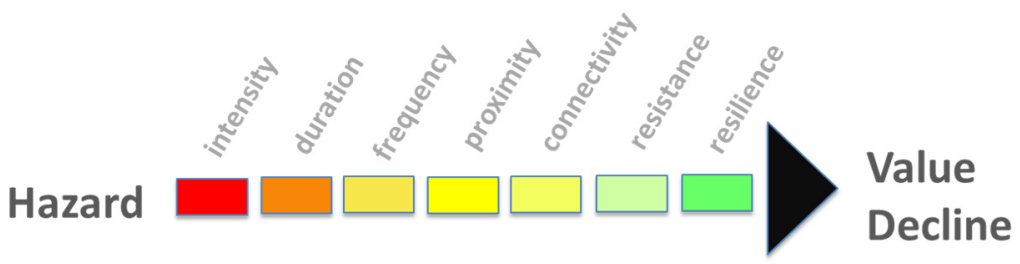

Figure 5: The risk pathway [9].

- Strategy 4a: Reduce hazard intensity, e.g. reduce pollutant toxicity (refer also Strategy 3).

- Strategy 4b: Reduce the duration of a hazardous event, e.g. provide sediment containment basins at construction sites.

- Strategy 4c: Reduce the frequency of a hazardous event, e.g. provide spill containment basins at on major roads.

- Strategy 4d: Reduce proximity of hazard to value, e.g. ensure adequate riparian buffer widths. 
- Strategy 4e: Reduce connectivity of hazard to value, e.g. disconnect downpipes from the stormwater network.

- Strategy 4f: Improve the resistance of the value to a hazard, e.g. provide rock armouring to creek banks to prevent scouring.

- Strategy 4g: Improve the resilience of the value and allow opportunities for the waterway to self-restore, e.g. improve the flushing of a lake or pond (refer also Strategy 1).

Strategy aims:

Qualifying criteria:

Site profile:

Examples:

"Cyan"

\section{STRATEGY 5: VALUE RECONNECTION}

To expand this value spatially;

To link to other value regions; or

To improve complimentary value sets due to synergies.

Waterways must have a section with high value and opportunity to expand or improve value.

"The Missing Link".

Davidson Street Project [10], Bancroft Weir, Barry's Weir.

RGB Code: $\mathrm{R}=0, \mathrm{G}=250, \mathrm{~B}=250$.

GIS mapping can help to locate areas with high recovery potential. The first step is to identify areas with high waterway value (refer also Strategy 1). Any adjacent areas need to be examined to identify opportunities to expand this value via the following sub strategies.

\subsection{Strategy 5a: Value expansion}

Where there are opportunities to expand outwards from existing nodes of high value, creation of new habitat areas will encourage local wildlife populations to expand into these new areas.

\subsection{Strategy 5b: Value reconnection}

Managing connectivity is identified as one of the key factors to improve resilience [11]. It has been shown that fragmentation of habitat can harm regional biodiversity. This strategy may be applied if there are opportunities to link several existing value nodes and create wildlife corridors. For example, there may be opportunity to construct a fishway or to reengage a floodplain that has previously been disconnected from a waterway.

\subsection{Strategy 5c: Complimentary functions}

Where there are potential complimentary or synergistic functions within existing high value nodes, there may be opportunity to improve the triple-bottom-line value of a waterway. For example, a new eco-tourism venture may be compatible with a national park or conservation area. For this to occur there needs to be an intersection of high value and a key need.

\subsection{Strategy 5d: Value restoration}

With a little seed funding it may be possible to harness nature's ability for self-restoration. A famous example of this is the reintroduction of apex predators to national parks which caused widespread improvements in the landscape. Investment into community-based behaviour change mechanisms can create chain reactions leading to greater environmental improvements. 


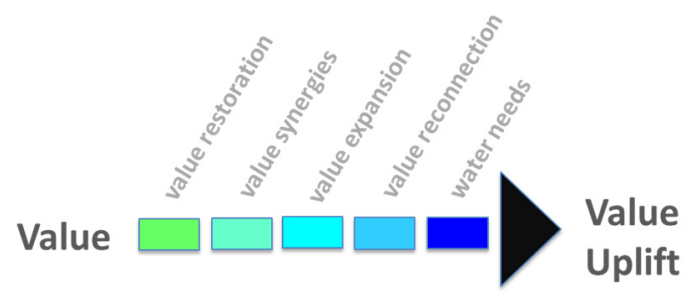

Figure 6: The opportunity pathway.

\section{STRATEGY 6: VALUE CREATION}

Strategy aims:

To meet the immediate needs of the community and the local ecology.

Qualifying criteria:

Catchments where there is little to harm in the way of existing waterway value.

Site profile:

Examples:

"The Blank Canvas".

"Blue"

Mackay's Cane Drains [12], Small Creek - Raceview [13].

RGB Code: $\mathrm{R}=0, \mathrm{G}=0, \mathrm{~B}=250$.

Since these sites are usually isolated from other areas of value, there may be a lower chance that these projects catalyse further value increases. These projects should therefore be evaluated on their own merit and may have limited benefit to adjacent catchments.

\subsection{Strategy 6a: Novel waterways}

With a blank canvas, Local Governments can create the exact waterways they want to fulfil a community or ecological need. The city of Mackay is surrounded by cane fields. As the urban footprint expands there is opportunity to recreate "natural" waterways from the highly modified cane drains (see Fig. 7) [12]. Ipswich City Council has invested considerable sums to re-naturalise a section of Small Creek that had been cleared of vegetation, straightened and hardened via a concrete channel [13]. These creek naturalisation projects create new opportunities for residents to interact with nature. They also provide new habitat for local wildlife.

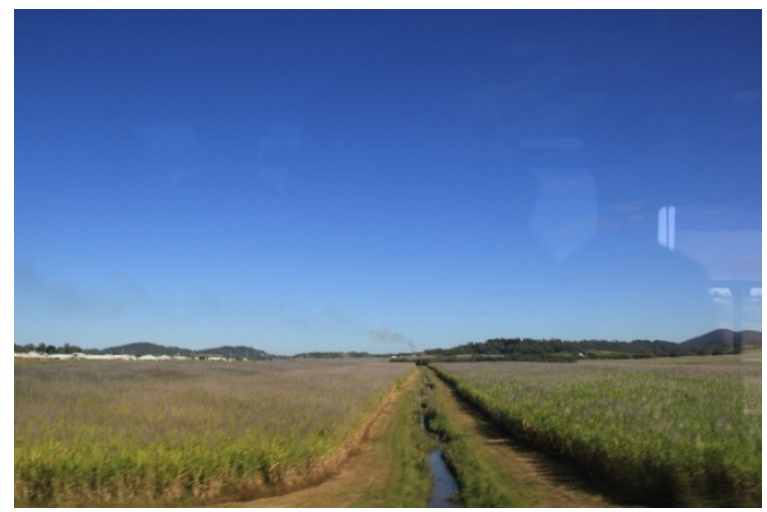

Figure 7: Cane Drain, Mackay. 


\subsection{Strategy 6b: Establishing refuges}

We can improve the survival chances for migratory species (e.g. birds) by creating high quality refuges (e.g. wetlands) in areas where there may be little surrounding value.

It may also possible to create refuges out of man-made lakes or wetlands and undertaking fish restocking programs. These areas can often form an important insurance policy against degradation and deterioration of waterways in other areas of the State.

Strategy aims:

Qualifying criteria:

Site profile:

Examples:

"Magenta"

\section{STRATEGY 7: GAMECHANGERS}

To use a waterway hazard to fulfil a community or ecological need.

Sites need to produce a suitable form of waterway hazard; There needs to be a mechanism to convert this hazard into a useful product;

There must also be a particular demand for the product close by. "Turning Trash into Treasure".

Redbank Plains Recreational Reserve [14], Jim Donald Park. RGB Code: $\mathrm{R}=250, \mathrm{G}=0, \mathrm{~B}=250$.

\subsection{Strategy 7a: Gamechangers}

Gamechangers are usually technology-based solutions and are underpinned by the principles of the Circular Economy where waste products are converted into a resource. Essentially it mimics nature where waste products are decomposed and form the building blocks of the next lifeform for example fallen leaves decompose and become fertiliser for the next growth cycle. This strategy may not be feasible in all circumstances but if these types of solutions are found they can neatly address a waterway hazard and provide additional benefits to the community or local environment.

Urban development can increase the amount of water flowing to creeks leading to bed and bank scour. However, there is a real need to diversify water resources in a changing climate. Stormwater can help displace the need for drinking water and can be used to irrigate lawns and gardens. There are also opportunities to harvest recycled rainwater for flushing toilets and laundries. As illustrated (Fig. 8), there are several prerequisites that are required in order to achieve successful game-changing outcomes.

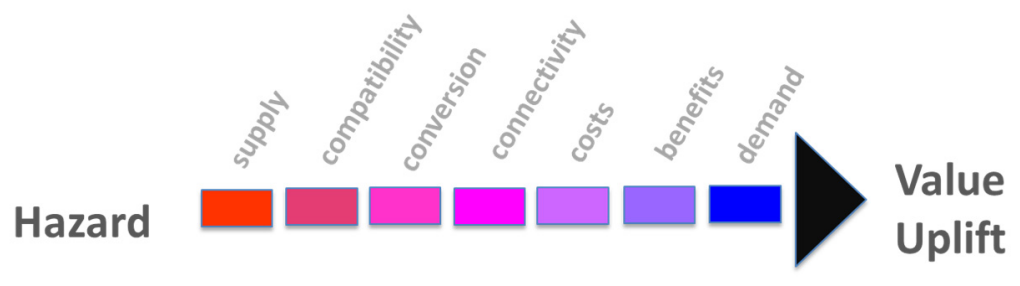

Figure 8: The gamechanger pathway.

The first prerequisite is to establish compatibility. Is there is a community, economic or environmental need for a particular hazard (e.g. can excess stormwater be used for irrigation)? The second prerequisite is to find locations where these hazards and needs intersect (Connectivity). Supply and Demand considerations need to be assessed. Stormwater 
harvesting systems cannot function at full productivity without a demand for non-potable water (e.g. an adjacent sports field to irrigate). The last prerequisite is to achieve an appropriate Cost/Benefit ratio (e.g. harvested stormwater is often too expensive when used as a drinking water supply due to high treatment and storage costs).

Other examples of gamechangers include drinking container deposit schemes (these fulfil economic needs as well as pollutant reduction) and using treated wastewater to recharge groundwater aquifers to prevent seawater intrusion into groundwater dependant ecosystems (these fulfil ecological needs as well as pollution reduction).

Strategy aims:

9 STRATEGY 8: STRATEGIC OFFSETS

Qualifying criteria: To redirect finance to areas where they will have a much bigger impact.

The donor site should not discharge to a high value waterway; It should be relatively stable (i.e. established urban areas); Adjacent waterways should have limited prospects for future recovery.

Site profile: "The Underperformer".

Examples:

Port of Brisbane [15], infill development in the Lower Norman Creek and Kedron Brook catchments.

"Grey" RGB Code: $\mathrm{R}=100, \mathrm{G}=100, \mathrm{~B}=100$.

There are four key scenarios where an offset can be legitimised.

\subsection{Strategy 8a: Waterways unlikely to improve from investment}

Where stormwater discharges directly to open ocean the benefits of a bioretention basin are unlikely to be as beneficial as in other circumstances. For example:

- Nutrient is managed by marine environment;

- Sediment is deposited on the sea floor;

- Flow change is unnoticed.

In this instance the same investment is best made upstream where it can have a bigger impact.

\subsection{Strategy 8b: Higher than average infrastructure cost}

There is a case for employing stormwater offsets in situations where a high percentage of money goes to ancillary works that are unrelated to stormwater treatment. For example, retaining structures may be required around bioretention basins on sites with steep land slope and services may require substantial relocating in retrofit applications at marginal ecological return on investment. If the same money was spent elsewhere it could have a much bigger impact.

\subsection{Strategy 8c: High missed opportunity cost}

Sometimes a proposed stormwater treatment measure will require allocation of too much premium land and another project on the same site would create a large economic return [15]. In this example, funds raised from commercial ventures in the CBD could contribute to a larger impact outside of the city CBD. 


\subsection{Strategy 8d: Insufficient funding for high impact projects}

Where high impact projects (e.g. regional wetlands) have been identified in other locations (i.e. via Strategies 1 to 7) but are not feasible due to a lack of funding, resources should instead be reallocated from low impact projects to these high impact projects.

Once a site is identified as an offsets donor (i.e. Strategy 8), it will often also qualify as a Strategy 9 site.

\section{STRATEGY 9: MINIMUM REQUIREMENTS}

Strategy aims:

To provide just the minimum amount of investment to prevent

Qualifying criteria: public safety risks and to avoid total sterilization of the waterway.

Site profile:

Examples: Every waterway should have a minimum amount of funding available to avert emergencies.

"Charcoal" "Left to their own devices".

Parts of the Bremmer, Oxley, Logan and Brisbane Rivers. RGB Code: $R=50, G=50, B=50$.

Note most of the funding drawn from these catchments is better invested elsewhere (refer to Strategies 1-7). Reasons to invest in these types of catchments however include:

\subsection{Strategy 9a: Avoid public safety risks}

Local governments generally have a duty to prevent harm and loss of life resulting from the following scenarios:

- Flooding caused by blocked culverts, bank destabilisation;

- Contamination of drinking water supplies;

- e-coli outbreaks - closed swimming beaches;

- Blue-green algae outbreaks and mass fish kills.

\subsection{Strategy 9b: Containment of threats}

There is an economic justification for the investment in this catchment where we can prevent hazards (e.g. weeds, invasive species) spilling over into neighbouring high value areas. Note these hazards need to be mobile.

\subsection{Strategy 9c: Thresholds}

If the waterway pollution threshold is exceeded it can lead to a sometimes-irreversible loss of value (i.e. biodiversity and species loss). We therefore need to understand the ecological thresholds of the waterway and avoid crossing this line.

\subsection{Strategy 9d: Seeds of change}

Small low-cost interventions can sometimes improve waterway value of their own accord with limited resources e.g. education and community based social marketing.

\section{CONCLUSION}

The current stormwater pollution regulations in Queensland are not leading the most effective waterway management strategy. The research behind this paper points to the need to explore 
different ways of managing our waterways. To this end, HLW has created the Strategic Waterways tool to assess the diverse values, hazards and needs of each waterway. From there, a unique intervention can be determined.

The main body of the paper details each of the nine possible waterway improvement strategies and outlines the scenarios where they will be most effective. This methodology allows waterway managers to construct a balanced portfolio of waterway management projects that will help to maintain, protect and enhance waterway value into the future.

\section{ACKNOWLEDGEMENTS}

Thanks, and acknowledgement must go to my colleagues at HLW especially Mr Adrian Crocetti for kindly reviewing this paper; the Department of Environment and Science for continual support of the Water by Design Program; Mr Tony Weber and Alluvium for undertaking the background scientific research for this project; and the broader stormwater industry for supporting our inquiries and providing feedback on our proposals.

\section{REFERENCES}

[1] Weber, T. et al., Stormwater Management Design Objectives, Alluvium, 2018.

[2] Browning, G.D., State Planning Policy: Expert Workshop Summary Report, Water by Design, 2020.

[3] Browning, G.D., Let's get our ducks in a row: Novel tools for waterway prioritisation. International Journal of Environmental Impacts, 2(1), pp. 42-58, 2019.

[4] Browning G.D., 50 shades of risk: A tool to analyse and prioritise complex waterway management. World Engineering Conference, Melbourne 2019.

[5] Healthy Land and Water, Report Card, 2019. https://reportcard.hlw.org.au/public/ media/2019-10-22/245c546b-704b-438f-a807-1068a0d33b5c/full.pdf.

[6] DES, Environmental Protection (Water) Policy, 2009.

[7] Water by Design State of the Streams, 2014 and 2017.

[8] Browning, G.D., Strategic waterways. Water by Design, 2019. https://waterbydesign.com.au/news/strategic-waterways

[9] Browning, G.D., Let's get our priorities straight. WIT Transactions on Ecology and the Environment, vol. 228, WIT Press: Southampton and Boston, 2018.

[10] Nasplezes, R., Davidson Street. Water by Design, 2019. https://waterbydesign.com.au/ case-study/davidson-street-newmarket.

[11] Stockholm Resilience Centre, Applying Resilience Thinking. www.stockholmresilience.org/download/18.10119fc11455d3c557d6928/1459560241 272/SRC+Applying+Resilience+final.pdf.

[12] Mullaly, J., Little McCready's Creek. Water by Design, 2019. https://waterbydesign.com.au/case-study/little-mccreadys-creek-rehabilitationmackay-regional-council.

[13] Mullaly, J., Small Creek. Water by Design, 2019. https://waterbydesign.com.au/casestudy/small-creek-ipswich-city-council.

[14] Browning, G.D., Redbank Plains. Water by Design, 2020. https://waterbydesign.com.au/case-study/redbank-plains-recreational-reservewetland.

[15] Port of Brisbane, Port of Brisbane website, 2020. www.portbris.com.au/MajorProjects/Offsite-Stormwater/. 